\title{
Efectos psicosociales de la desaparición forzada de jóvenes en Latinoamérica: una tarea pendiente
}

\author{
Sandra Milena Serrano-Mora, Ph. D. ${ }^{\text {a }}$ \\ Universidad de Santander, Colombia \\ Marieta Quintero-Mejía, Ph. D. ${ }^{b}$ \\ Universidad de Manizales, Cinde, Colombia
}

sserrano@udes.edu.co

\section{Resumen (analítico)}

Este artículo realiza una revisión del concepto de trauma psicosocial desde los fenómenos de violencia política en Latinoamérica y, en concreto, sobre la desaparición forzada de jóvenes en Colombia.

Desde este análisis teórico-contextual, se plantea cuáles han sido las afectaciones personales, familiares y colectivas (atributos del trauma psicosocial) que este fenómeno de la desaparición forzada ha generado en el tejido social colombiano. A manera de reflexión final, las autoras proponen la necesidad de repensar las afectaciones psicosociales que han sido estudiadas de manera general, a partir de los daños a la sociedad representados en el hecho de desaparecer específicamente jóvenes y las implicaciones que esto ha tenido para el entramado social.

\section{Palabras clave}

Conflicto armado; desaparición forzada; jóvenes; trauma psicosocial; tejido social.

\section{Thesauro}

Tesauro de Ciencias Sociales de la Unesco.

\section{Para citar este artículo}

Serrano-Mora, S. M., \& Quintero-Mejía, M. (2022). Efectos psicosociales de la desaparición forzada de jóvenes en Latinoamérica: una tarea pendiente. Revista Latinoamericana de Ciencias Sociales, Niñez y Juventud, 20(1), 1-23.

https://dx.doi.org/10.11600/rlcsnj.20.1.4475

\section{Historial}

Recibido: 04.08.2020

Aceptado: 04.03.2021

Publicado: 17.12.2021

\section{Información artículo}

Este artículo hace parte del proyecto Trauma psicosocial en Colombia: narrativas de víctimas/sobrevivientes de desaparición forzada en el postacuerdo, realizado para optar al título de Doctora en Ciencias Sociales, Niñez y Juventud de la Universidad de Manizales-Cinde, en la línea de investigación infancias, juventudes y ejercicio de la ciudadanía. Este proyecto fue aprobado para la candidatura al título, el 13 de abril del 2018 y fue entregado a evaluadores el 30 de noviembre de 2019. Área: psicología. Subárea: psicología. 


\section{Psychosocial effects of the forced disappearances of young people in Latin America: A pending task}

\section{Abstract (analytical)}

This article reviews the concept of psychosocial trauma based on the phenomena of political violence in Latin America and specifically the forced disappearance of young people in Colombia. Based on this theoretical-contextual analysis, the study identifies that this phenomenon of forced disappearance has generated personal, family and collective affectations - involving attributes of psychosocial trauma - in the Colombian social fabric. As a final reflection, the authors propose the need to rethink the psychosocial effects of the damage to society caused by this violence, represented in the fact that young people have been forcibly disappeared and the implications that this has had for the social fabric.

Keywords

Armed conflict; enforced disappearance; youths; psychosocial trauma; social fabric.

\section{Efeitos psicossociais do desaparecimento forçado de jovens na América Latina: Tarefa pendente}

\section{Resumo (analítico)}

Este artigo revisa o conceito de trauma psicossocial a partir dos fenômenos de violência política na América Latina e, especificamente, do desaparecimento forçado de jovens na Colômbia. A partir desta análise teórico-contextual, considera-se quais foram as consequências pessoais, familiares e coletivas —atributos do trauma psicossocial_ que este fenômeno de desaparecimento forçado tem gerado no tecido social colombiano. Como reflexão final, os autores propõem a necessidade de se repensar os efeitos psicossociais que vêm sendo estudados de forma geral, a partir dos prejuízos à sociedade representados pelo desaparecimento específico dos jovens e das implicações que isso teve para a rede social.

\section{Palavras-chave}

Conflito armado; desaparecimento de pessoas; jovens; trauma psicossocial; tecido social.

Información autoras

[a] Psicóloga. Magíster en Desarrollo educativo y social, Universidad Pedagógica Nacional-Cinde. Doctora en Ciencias Sociales, Niñez y Juventud, Universidad de Manizales-Cinde. Profesora investigadora Instituto Investigaciones Atulaa, Universidad de Santander. (iD 0000-0002-5670-2699. H5: 2. correo electrónico: sserrano@udes.edu.co

[b] Posdoctora en Ciencias Sociales, Niñez y Juventud, Red Clacso de postgrados. Profesora del Doctorado en Ciencias Sociales, Niñez y Juventud, Cinde-Universidad de Manizales. ID 0000-0002-8001-4511. H5: 10. Correo electrónico: marietaqmg@gmail.com 


\section{Introducción}

【a desaparición forzada, con un alto porcentaje de jóvenes como sus principales américa en el marco de las violencias políticas vividas en distintos momentos sociohistóricos que cada país ha enfrentado. Tal es el caso de Guatemala (1960-1996), Perú (1980-200o), El Salvador (1979-1992) y las dictaduras de Chile (1973-1990) y Argentina (1976-1983). En el caso de Colombia, ${ }^{1}$ la desaparición forzada es un hecho particularmente complejo y doloroso, no solo por sus características, sino por las huellas que prevalecen en quienes sobreviven al desaparecido, su familia y la comunidad a la que pertenecía.

En este artículo se realiza un análisis sobre la configuración del trauma psicosocial en un plano conceptual-contextual, dado que se parte de un hecho victimizante concreto, la desaparición forzada de jóvenes, fenómeno que ha emergido en el marco de la violencia política latinoamericana, con las distintas particularidades del mismo; por ejemplo, en razón a las prácticas y dinámicas generadas en el proceso de desaparición en la dictadura argentina (Calveiro, 2014) o las implementadas en el caso colombiano, país en el cual la desaparición forzada ha variado desde la detención ilegal hasta el fenómeno conocido como «falsos positivos» o ejecuciones extrajudiciales. ${ }^{2}$ Todo esto ha motivado investigaciones relacionadas con el conflicto armado y la desaparición forzada (durante los últimos 20 años) entre los profesionales de las ciencias sociales, en aras de la generación

\footnotetext{
${ }^{1}$ El conflicto interno colombiano fue legalmente reconocido hasta el año 2011, con la sanción de la Ley 1448 o Ley de víctimas. Para historiadores como González (2014), las violencias se han gestado a lo largo de una compleja historia de poder y dominio por el territorio, los medios de producción e influencia económica en el país, conjugando condiciones estructurales objetivas y subjetivas que, hasta la fecha, lo mantienen. De hecho, es catalogado como el conflicto interno más largo de Latinoamérica.

${ }^{2}$ Recientemente, el 18 de febrero de 2021, la Justicia Especial para la Paz, uno de los organismos que surgieron del acuerdo de paz con las Fuerzas Armadas Revolucionarias (2016), confirmó la priorización del caso o3 conocido como el de falsos positivos, en el que se estableció que por lo menos 6402 personas fueron desaparecidas y, posteriormente, asesinadas ilegítimamente para ser presentadas como bajas en combate por agentes del Estado.
} 
de marcos analíticos que permitan contar con referentes objetivos que nos permitan dimensionar la magnitud del sufrimiento y el daño causados.

En un principio, los estudios sobre las afectaciones de la violencia política en Latinoamérica centraron su interés en las expresiones físicas, psicológicas e individuales de un trauma producto de la vivencia de hechos tales como detenciones arbitrarias, masacres o desapariciones forzadas. Pero en 1988, el psicólogo jesuita Martín-Baró propuso un análisis más colectivo de las afectaciones sociales frente a la vivencia de un conflicto prolongado, partiendo de la experiencia de la guerra en El Salvador. Posteriormente, en Chile, los investigadores Lira y Castillo (1991) llamaron la atención sobre la psicología de la amenaza política y el miedo, desde el Instituto Latinoamericano de Salud Mental y Derechos Humanos. También Blanco y Díaz (2004) propusieron una mirada mucho más amplia y social de las condiciones del estrés postraumático a partir de las experiencias de los atentados terroristas en Nueva York (2001), España (2004) y Bogotá (2003).

Teniendo en cuenta lo planteado, el análisis que ocupa este artículo parte de dos premisas fundamentales: la primera es comprender las dimensiones de esas afectaciones psicosociales que se han instalado a partir de la vivencia del conflicto interno colombiano, mientras que la segunda es plantear la reflexión en torno a los jóvenes que han sido utilizados en estos marcos de violencia política para agudizar dichas afectaciones psicosociales, no solo en el plano físico, sino también simbólico, dada su representatividad social.

Frente a la primera premisa, los impactos personales, familiares y comunitarios de los hechos violentos, autores como Beristain (2018) lo han planteado, refiriéndose a que las catástrofes sociopolíticas (tales como guerras o estados de terror promovidos por regímenes políticos) contribuyen, no solo a la desestructuración de las instituciones, sino también impactan directamente situaciones, personas y hechos.

Asimismo, Gómez (2015) plantea que las comunidades que viven en contextos de guerra construyen subjetividades colectivas que indiscutiblemente ponen en tensión el sentido del buen vivir. De igual manera, estas violencias afectan, no solo el nivel individual, sino también generan desconexión con la realidad. En este sentido, estos impactos de la violencia política también tienen implicaciones en la interacción con la dimensión de salud de las poblaciones, indicando que las dimensiones salud y paz se interrelacionan y tienen impactos en el campo individual y colectivo (Franco, 2018).

Es así como los análisis de la salud de la población civil, a partir de la exposición a un conflicto armado como el colombiano, expresan la complejidad del tema: 
En Colombia la población civil sufre los efectos de una crisis humanitaria que la convierte en víctima silenciosa del conflicto armado, exponiéndola a situaciones como desplazamiento forzado, masacres, confinamiento, detenciones arbitrarias, desapariciones forzadas con efectos sobre la salud mental y la calidad de vida de los individuos y las comunidades. (Instituto Nacional de Salud, 2017, p. 199)

Frente a la segunda premisa de análisis, la de la utilización de los jóvenes como medios para violentar, no solo en el plano individual, sino subjetivo y social, este ha sido un hecho recurrente en las dinámicas violentas vividas en América Latina y, concretamente, en Colombia. Tal como lo expresa Bajtín (1993, como es citado por Amador-Baquiro, 2016), la condición juvenil es una construcción social que no solo parte de su enunciación desde un afuera, sino especialmente de las experiencias concretas de estos sujetos en el mundo de la vida; por ello, su representación social es compleja, en tanto son figuras simbólicas que denotan en sí mismos las propias posibilidades de una comunidad, la energía, la vitalidad y la esperanza que en sus rostros reflejan.

Tal como lo expresan Trucco y Hullmann (2015), la condición juvenil en Latinoamérica ha tenido un correlato sociohistórico en el que, dependiendo de las características y dinámicas de los sistemas violentos, en algunas ocasiones han sido víctimas y en otras han ocupado el lugar de victimarios.

Ahora bien, en el caso de los jóvenes como víctimas, receptores directos de un hecho sistemático como la desaparición forzada, los datos nos permiten dar cuenta de la magnitud del mismo. En el caso de Guatemala, la Organización de Naciones Unidas (1999), a través de la Comisión para el Esclarecimiento Histórico, «registró un total de 61648 violaciones de derechos humanos, de las cuales 6159 corresponden a casos de desaparición forzada entre 1979 y 1983» (p. 407). En el caso de ese país, estas afectaciones también tuvieron un carácter étnico, dadas las características de jóvenes provenientes de diferentes comunidades indígenas que fueron violentados.

En el caso de El Salvador, la Comisión de la Verdad registró cerca de 22 ooo denuncias de graves hechos de violencia, ocurridos en el período de enero de 1980 a julio de 1991. Más del 60 \% correspondieron a ejecuciones extrajudiciales, más del $25 \%$ a desapariciones forzadas y más del $20 \%$ incluyeron denuncias de tortura (ONU, 1993, p. 41).

En Chile, durante en el período de dictadura militar (entre el 11 de septiembre de 1973 y el 11 de marzo de 1990), el informe de la Corporación Nacional de Reparación y Reconciliación (1996) realizó un análisis de las dinámicas y características aplicadas a las 
víctimas de desaparición forzada, entre las que se encontraban simpatizantes de ciertos colectivos políticos, pero también jefes y dirigentes políticos, sindicales, vecinales (juntas de vecinos, centros de madres y las Juntas de Abastecimientos y Control de Precios), poblacionales, indígenas y estudiantiles. Muchas veces, no obstante, dichas relaciones políticas se deducían de la conducta conflictiva de la víctima en huelgas, paros, tomas de terrenos o de predios, manifestaciones callejeras, etc.

En Argentina, durante la dictadura militar fueron desaparecidos 8961 jóvenes, según la Comisión Nacional sobre la Desaparición de Personas ([Conadep], 1984); esta aclara que pueden ser más, pues muchos ingresaron a los centros de detención con apodos y en otros casos los familiares nunca denunciaron. Según esta Comisión, los detenidos-desaparecidos tenían los siguientes rangos de edad y porcentajes: de 16 a 20 años (10.6\%), de 21 a 25 años (32.62\%) y de 26 a zo años (25.90\%) (p. 222).

En el caso colombiano, según el Registro Único de Víctimas (2021), adscrito a la oficina de Unidad de Víctimas del país, el dato de desaparecidos asciende a 187673 ; este registro se extiende desde el año 1985 a junio de 2021. Al filtrar este dato por ciclo vital se evidencia que un alto número de afectados fueron jóvenes entre los 12 y 17 años (2877 desaparecidos) y entre 18 a 28 años (17 895 desaparecidos).

Este panorama general, reflejado en datos concretos frente a desaparición forzada, nos ayuda a señalar la pertinencia del análisis que aquí se plantea en torno a este rastreo del concepto de trauma psicosocial a la luz de este hecho victimizante; este ha sido recurrente en los informes de las comisiones de verdad que se han desarrollado en Latinoamérica y que requiere aportar sus análisis al campo problémico de la juventud latinoamericana, sus incertidumbres y sus posibilidades.

De esta manera, se plantea la línea de reflexión de este artículo, en torno a tratar de entender, siguiendo el caso colombiano, ¿cómo la desaparición forzada de jóvenes ha representado una forma de constitución del trauma psicosocial?

\section{Método}

Para construir este análisis se acudió a la aproximación analítica-comprensiva, la cual se ubica en la perspectiva de la investigación histórico-hermenéutica. En palabras de Vasco (1990), «se trata de dar una interpretación global a un hecho, de comprenderlo, de darle el sentido que tiene para el grupo que está comprometido en esa praxis social» (p. 14). 
Para el proceso de análisis se utilizó el recurso metodológico de la revisión documental. De acuerdo con los lineamientos establecidos por Bernal-Torres (2016), este proceso incluyó las siguientes fases: a) revisión de treinta documentos de soporte histórico/teórico de la desaparición forzada y del trauma psicosocial; b) elaboración de fichas descriptoras de los documentos; c) identificación de los dos núcleos temáticos que dan soporte a los resultados. Estos dos núcleos son: carácter psicosocial del trauma por la vía de desaparición forzada en la violencia política y afectaciones psicosociales desde la desaparición forzada de jóvenes en Colombia.

Como criterios de inclusión y selección de las fuentes de datos se tuvieron en cuenta: 1) la conexión y pertinencia del documento con los dos núcleos temáticos; 2) el aporte al análisis desde Latinoamérica; y 3 ) el abordaje social de la desaparición forzada más allá de las implicaciones psicológicas individuales ampliamente descritas.

Como estrategia de análisis de datos se recurrió al análisis artesanal, el cual permitió el proceso de interpretación a partir de saturación de las categorías emergentes y posterior construcción analítica por cada núcleo temático establecido. A continuación, se presentan los elementos interpretativos encontrados a partir de este análisis documental en los dos núcleos temáticos.

\section{Desarrollo/análisis}

\section{Carácter psicosocial del trauma por la vía de desaparición forzada en la violencia política}

Se reconoce la violencia política vivida a través de la desaparición forzada como una estructura planeada y pensada para neutralizar a posibles enemigos del orden establecido, lo cual ha tenido serias implicaciones en la salud mental individual y colectiva, que supera la noción individual de trauma. Así lo manifiestan Posada y Parales (2012) cuando afirman que no se trata de los síntomas o trastornos psicológicos, sino de las particularidades del conocimiento social de los individuos y sus las relaciones sociales.

Esta noción colectiva del trauma no solo se ha rastreado desde la violencia política latinoamericana, sino también desde los análisis realizados después de la segunda guerra mundial. Así lo explica Ortega (2011) cuando plantea cómo se alteran a partir de una vivencia sostenida y traumática de hechos que generan una dislocación masiva de relaciones, 
instituciones y funciones sociales de un grupo determinado, como fue el caso de lo vivido por los judíos en los campos de concentración.

Es así como, por la vía de los hechos sociales, este concepto de trauma (que en sus orígenes estaba asociado a condiciones individuales, a respuestas fisiológicas, comportamentales o emocionales como producto de un evento vivido) empezó a adquirir otras dimensiones que desbordaron lo individual y se englobaron en lo que hoy en día se reconoce como condiciones psicosociales. Conformando así un corpus de conocimiento que se ha venido consolidando en sus estudios y alcances con aportes de teóricos que se ubican con mucha fuerza en Latinoamérica, especialmente por los múltiples hechos de violencia política que en diferentes momentos y condiciones han experimentado los habitantes de los países en esta región.

En este sentido, podría afirmarse que los hechos vividos en la guerra civil de El Salvador (1979-1992), en el conflicto interno en Guatemala (1960-1996), en las dictaduras de Argentina (1976-1981) y Chile (1973-1990), así como en el conflicto interno colombiano (1960 a la fecha), por solo mencionar algunos, calificarían dentro de una vivencia de hechos que están en los límites de la experiencia humana. Estos han llevado a los individuos, a sus familias y a las comunidades a experimentar situaciones de dolor físico, psicológico y simbólico por fuera de cualquier rango que se pueda clasificar como normal (Ortega, 2011).

El autor que dio forma a esta idea del carácter psicosocial del trauma fue el jesuita y psicólogo Martín-Baró (1990), a partir de su cercanía y análisis de la experiencia vivida por la guerra civil salvadoreña. Según este autor, las características de este trauma psicosocial se expresan en tres elementos: su carácter dialéctico; sus condiciones de producción instaladas en el contexto social; y la conformación de un ethos, es decir, comunidades traumatizadas, a partir de acontecimientos extraordinarios. De acuerdo con esto, los autores Hernández y Blanco (2005) llaman la atención sobre la necesidad de evaluar el contexto del sujeto que sufre:

Parece necesario, entonces, mirar no solo al sujeto, sino a aquello que le rodea por si algunos de los componentes de su medio pudieran ayudarnos a comprender mejor lo que hace, lo que siente (en este caso, lo que sufre) y lo que piensa. La necesidad de recuperar el contexto: ese es nuestro argumento primordial a la hora de hablar de trauma psicosocial. (p. 4)

Lo anterior implica reconocer esas diferentes perspectivas sociohistóricas, su condición cultural y las afectaciones o daños causados más allá de la perspectiva individual del sujeto que sufre, directamente, un hecho violento. 
Esta noción más colectiva se refleja en los informes de las comisiones de verdad que algunos países han tenido como parte de la firma de acuerdos de paz. Por ejemplo, la Comisión para el Esclarecimiento Histórico (1999) en Guatemala lo afirmó así:

Lo que ha sido destruido es más amplio que las nociones de trauma interno individual. Extendido en el tiempo, el trauma psicosocial involucra la destrucción de arquetipos y metáforas culturales, aniquilando o limitando profundamente las posibilidades de la próxima generación de afirmar aspectos de su vida cultural. (Comas-Díaz et al., 1998, p. 782, como son citados por Dobles, 2009, p. 81)

En el caso de la Argentina, la Conadep (1984) describió los efectos generados por la desaparición de los jóvenes detenidos ilegalmente en los centros organizados para ello durante la dictadura militar, los cuales claramente se instalaron en sus familias y en los mensajes que se dirigían a la comunidad en general:

Fue otra de las formas de paralizar el reclamo público, de asegurarse por un tiempo el silencio de los familiares. Precisamente, alentando en ellos la esperanza de que su ser querido estaba con vida, manteniéndolo en la imprecisa calidad de persona desaparecida, se creó una ambigüedad que obligó al aislamiento del familiar, a no hacer nada que pudiera irritar al Gobierno. (p. 179)

Por otra parte, autores como Lira y Castillo (1991) han documentado la noción social del trauma, haciendo referencia al daño causado en las estructuras e instituciones sociales. De esto da cuenta la represión en Chile y Argentina:

El daño producido no es simplemente el de la vida personal que se destruye, el daño se ha causado a las estructuras sociales mismas, a las normas que rigen la convivencia, a las instituciones que regulan la vida de los ciudadanos, a los valores y principios con los que se ha educado y en función de los cuales se ha intentado justificar la represión. (Lira \& Castillo, como son citados por Dobles, 2009, p. 76)

En este sentido, los autores han propuesto la ampliación de los análisis acerca de las afectaciones psicosociales, llamando la atención sobre contextos de violencia política que gestan condiciones traumáticas muy difíciles de atender, pues las condiciones de contexto no son susceptibles de cambio al no ser percibidas como las generadoras del trauma.

Lira (2010), a propósito del trabajo psicosocial y terapéutico efectuado en Chile después del régimen militar, afirma que las torturas, desapariciones y asesinatos fueron 
asumidos como condiciones potencialmente traumáticas que afectaron esa condición de sujetos sociales activos y participativos.

En el caso peruano, también se describió cómo el miedo y la desconfianza silenciaron a la gente y debilitaron los lazos comunitarios:

Fuertes conflictos de relación, debilitamiento y desarticulación de las organizaciones sociales, pérdida de las redes de protección social, estigmatización de las personas y comunidades; todo lo cual afectó las identidades personales y colectivas y causó la pérdida de costumbres, celebraciones y ritos comunitarios. (CVR, 2003, como es citada por Moyano, 2009, p. 15)

En El Salvador, territorio que sirvió para acuñar este concepto psicosocial, MartínBaró (1988) afirmaba: «El trauma psicosocial experimentado por las personas denota entonces unas relaciones sociales enajenantes, que niegan el carácter humano del "enemigo", al que se rechaza como interlocutor en cuanto tal y al que incluso se busca destruir» (p. 138).

En suma, las dinámicas de violencia política que han caracterizado el devenir histórico y social de Latinoamérica, indudablemente han contribuido a la gestación de un trauma psicosocial que ha permeado las interacciones sociales, la comunicación y los lazos más profundos de lo que se reconoce como el tejido social, deteriorando la convivencia, la confianza y, en general, las interacciones sociales. Es decir, el trauma socava las relaciones sociales, deteriora la convivencia e introduce polarización entre las personas (Díaz et al., como son citados por Yubero et al., 2007, p. 18).

Finalmente, se puede afirmar que este carácter psicosocial del trauma establece una relación dialéctica entre individuo y sociedad:

Porque todo hecho de violencia política dirigido a un individuo en particular pretende causar un daño a nivel colectivo y de igual manera, todo hecho violento dirigido a un colectivo, genera además un daño específico en la constitución de cada individuo que se ve implicado directa o indirectamente en este. (Betancur \& Castro, 2015, p. 106)

Ahora bien, ¿cómo se conecta este concepto del trauma psicosocial por la vía de la violencia política con el hecho especifico de la desaparición forzada? En este segundo aspecto, es central plantear la idea alrededor de la cual este fenómeno de desaparecer jóvenes es un ingrediente decisivo en la estructuración de un trauma psicosocial porque 
es un hecho compartido con algunas de las experiencias latinoamericanas. No obstante, se hará referencia específica a las particularidades de este fenómeno en Colombia.

\section{Afectaciones psicosociales desde la desaparición forzada de jóvenes en Colombia}

La desaparición forzada se define desde el punto de vista jurídico como «la violación de múltiples derechos humanos y constituye un crimen de lesa humanidad. En el marco de la violencia sociopolítica, la desaparición forzada es una práctica premeditada y elegida en sus significados y mensajes» (Centro Nacional de Memoria Histórica, [CNMH], 2014, p. 53).

También se trata de un hecho victimizante atroz. Tal como lo afirma el CNMH (2016), «la desaparición forzada refleja el drama y el sufrimiento de los familiares, la desprotección del Estado y la barbarie de los desaparecedores quienes niegan los valores que sustentan la convivencia humana y el respeto por la dignidad y la vida» (p. 33).

En el ámbito psicológico y social, la desaparición «es una experiencia de carácter traumático que lesiona gravemente y de manera integral no solo el psiquismo individual de los familiares y las personas cercanas al entorno social de la persona desaparecida, sino a la sociedad en general» (CNMH, 2014, p. 53). De acuerdo con el equipo investigador del CNMH (2016), en Colombia tres son los propósitos en la desaparición forzada:

(1) Castigar y dejar mensajes aleccionadores tendientes a inhibir ideologías y prácticas políticas y sociales; (2) generar terror y así ganar y ejercer control, debido al potencial simbólico de este delito, y (3) ocultar crímenes, eliminando los cadáveres de las víctimas y borrando evidencias, para así dificultar que los delitos cometidos sean juzgados o para manipular y tergiversar las cifras. (p. 162)

También se ha estudiado la desaparición forzada como una forma de tortura que supera la noción de imprimir dolor en un cuerpo como medio para extraer información al torturado. En este caso, se trata de torturar con la incertidumbre, al condenar a la familia a una ausencia total de información respecto del paradero, la vida o la muerte del desaparecido. Además de afectar las interacciones de la familia como miembro de la comunidad:

Esto puede deberse a los nuevos sentimientos de falta de confianza en otras personas, a la sensación de vergüenza y suciedad causadas por el abuso sexual, el asesinato o desaparición de miembros de la familia y amigos. Las obligaciones sociales normales, incluida la 
buena vecindad, las actividades de la comunidad y la confianza en las instituciones gubernamentales locales y en la política nacional, pueden verse seriamente comprometidas, haciendo los esfuerzos de reconstrucción extremadamente difíciles. (Mollica, 1999, p. 55)

Desde la misma definición de esas características, propias de la desaparición forzada como medio y como fin, se ha hecho explícito ese carácter dialéctico, en tanto afectación directa al individuo desparecido y afectación indirecta a la familia y comunidad:

Mediante la práctica de la desaparición forzada, también se pretendió obtener información de las víctimas sobre los planes y actividades de los grupos insurgentes, de la oposición y de cualquier forma de organización contraria a los intereses del régimen establecido; castigar a las víctimas - y por intermedio de estas a la familia, a la comunidad y a la organización - mediante la aplicación de torturas y la propagación del terror recurriendo al ocultamiento del detenido y las amenazas contra sus familiares a fin de reprimir o paliar cualquier intento por conocer su paradero. (ONU, 1999, p. 414)

Ahora bien, a partir de la literatura disponible respecto de los análisis de la desaparición forzada como fenómeno violento, se podrían plantear varias dimensiones de la misma. Para efectos de la reflexión que ocupa este artículo, solo se mencionarán tres: 1) la duda frente al desaparecido y su familia; 2) la desaparición legitimada institucionalmente; y 3) la deshumanización y sistematicidad de la desaparición forzada.

\section{Duda y desconfianza frente al desaparecido y su familia}

Tiene que ver con un halo de duda, no solo frente a quien es desaparecido (sus posturas, actividades e ideales políticos), sino también frente a su familia. Es susceptible de sospecha aquel que puede asumir convicciones políticas contrarias a las del sistema establecido y este solo hecho le puede hacer acreedor a vigilancia, investigación o seguimiento: «el círculo de impunidad inicia con la estigmatización y señalamiento de las víctimas que aparecen reseñadas en los informes de inteligencia militar como guerrilleros o auxiliadores de la insurgencia» (Mignorance \& Arellana, 2019, p. 69).

Ante la desaparición forzada, la familia queda en suspenso, no solo por ser sometida a la misma sospecha, sino por no contar con las respuestas necesarias para dar fin a la incertidumbre en la que queda sumida:

En tales condiciones la desaparición de una persona coloca a la familia en una situación de extremo dolor y sufrimiento, debido a que es sometida a un intenso nivel de tensiones 
que se prolonga indefinidamente en el tiempo y cuya resolución es experimentada con gran incertidumbre. (Díaz \& Madariaga, 1997, como son citados por CNMH, 2014, p. 53)

\section{La desaparición legitimada institucionalmente}

En la mayoría de los casos, la desaparición ocurría de manos de autoridades oficiales; tal es el caso de Argentina o de Chile. En el informe de la Corporación Nacional de Reparación y Reconciliación (1996) de Chile, se plantea:

Con detenidos/desaparecidos, se alude a la situación de quienes fueron detenidos por agentes de la autoridad o por personas a su servicio, siendo la última noticia que se tuvo de ellos que fueron aprehendidos o que se les vio posteriormente en algún recinto secreto de detención. La autoridad niega haberlos detenido, o bien declara haberlos liberado luego de un cierto periodo de tiempo, entrega otras explicaciones insatisfactorias o simplemente guarda silencio. (p. 18)

De igual forma, en el caso colombiano, la investigación y documentación de la desaparición forzada llevó a los investigadores a plantear que, de forma similar a lo ocurrido en otros países de América Latina, esta se asoció a prácticas de los militares que incluían la represión, en donde las víctimas eran detenidas y luego desaparecidas, convirtiéndose en un crimen de Estado (CNMH, 2018).

Los informes también han documentado diferentes momentos y características de las prácticas de desaparición forzada en el país, las cuales conectan con las dinámicas coyunturales del conflicto armado interno que se ha mantenido en el escenario nacional por décadas. Al respecto, en el primer período destacan las fuerzas de seguridad estatales como perpetradoras, mientras que en el segundo y tercer período los grupos paramilitares, los cuales en muchas ocasiones articulan sus actividades con fuerzas estatales (CNMH, 2014):

En el periodo 1970-1981, se señala a los agentes de seguridad del Estado y a las organizaciones paramilitares de la época como responsables de este crimen de manera dominante, cuando esta comenzó a practicarse como una respuesta contrainsurgente del Estado ante el surgimiento de las guerrillas, y al amparo de la declaración sucesiva y prolongada de Estados de excepción, que menoscabaron la condición democrática del país. En el periodo entre 1982-2005, todavía articulados o apoyados por algunos agentes del Estado, quienes se convierten en sus máximos responsables. (CNMH, 2016, p. 19) 
Más recientemente, entre 2006-2015, los grupos armados paramilitares, que persisten después de su desmovilización, tienen la prevalencia como responsables de este delito (CNMH, 2018, p. 52). Ello implicaba - y continúa implicando- un fuerte golpe a las nociones de confianza y seguridad que una sociedad puede tener frente a aquellos que se supone están para proteger y garantizar derechos:

En este sentido, el papel de las fuerzas militares como protector es desvirtuado dado su protagonismo como perpetrador. Esto lesiona gravemente el orden social en el que se espera una actuación ajustada propia de su mandato en el marco de la convivencia basada en los derechos humanos en un país democrático. (CNMH, 2014, p. 45)

También lo menciona Calveiro (2014), a propósito del poder ejercido por los militares en la dictadura Argentina sobre esos cuerpos que desaparecían a su antojo:

Un poder disciplinario-asesino, un poder burocrático-asesino, un poder que se pretende total, que articula la individualización y la masificación, la disciplina y la regulación, la normalización, el control y el castigo, recuperando el derecho soberano de matar. Un poder de burócratas ensoberbecidos con su capacidad de matar, que se confunden a sí mismos con Dios. Un poder que se dirige al cuerpo individual y social para someterlo, uniformarlo, amputarlo, desaparecerlo. (p. 59)

\section{La deshumanización y sistematicidad de la desaparición forzada}

Un tercer aspecto es el de la deshumanización: la cosificación del ser humano (Uribe, 2009) al ser tratado como un objeto del cual se puede disponer en cualquier momento o lugar, sin tener que dar explicaciones de su paradero o de los tratos infrahumanos a los que muchas veces eran sometidas las personas una vez eran desaparecidas; hace alusión a ese poder casi divino que anula selectivamente (a su antojo prácticamente) todos los vestigios de humanidad de un individuo (Calveiro, 2014).

El otro aspecto es la sistematicidad de la desaparición. No se trataba de hechos aislados, sino de mecanismos intencionados que implicaban todo un proyecto social para quitar, desaparecer y eliminar a todo aquel que no estuviera en consonancia con los valores o las formas sociales concebidas como correctas.

Por esta razón, la desaparición en el caso argentino, chileno y colombiano, se trató de miles de personas, en su mayoría jóvenes, que podían representar los riesgos de un orden establecido: «la figura de la desaparición, como tecnología del poder instituido, 
con su correlato institucional, el campo de concentración-exterminio hicieron su aparición estando en vigencia las llamadas instituciones democráticas» (Calveiro, 2014, p. 27).

Adicionalmente, esta característica democrática bajo la cual se escudaban los victimarios facilitaba el empleo de métodos de ocultamiento de su identidad, el uso de capuchas y el empleo de vestimenta civil sin portar identificación, de manera que no era fácil asociarles con las entidades e instituciones a las cuales pertenecían. También las acciones violentas llevadas a cabo en horarios nocturnos, en fines de semana o días festivos, utilizar parajes solitarios o trasladar a los detenidos a guarniciones militares e incomunicarlos, entre otras (Guatavita, 2014).

Otro elemento de reflexión que surge en este entramado violento y que representa este hecho de la desaparición forzada es su uso como forma de exclusión y eliminación de aquellos que eran catalogados como indeseables, sospechosos o desadaptados:

Junto con la ejecución de la desaparición en zona rural y de población marginal o estigmatizada en la sociedad colombiana: trabajadoras sexuales, jóvenes que trabajan en la calle, miembros de la comunidad LGTB, consumidores de drogas, habitantes de calle, personas con discapacidad, entre otros, continuó la desaparición contra militantes de izquierda. (Guatavita, 2014, p. 46)

De la misma manera, la mencionada sistematicidad de la desaparición de jóvenes se conectó con un sinnúmero de delitos a los que daba lugar:

Desapariciones masivas, masacres, desapariciones progresivas y sistemáticas, amenazas, exilio, secuestro, detención ilegal, violencia sexual, maltrato físico, allanamiento ilegal, ejecuciones extrajudiciales, respuesta del Estado por fuera del orden jurídico, genocidio, exterminio, tortura física y psicológica, asesinato, intimidación, captura de familiares que intentan defender a sus familiares desaparecidos, desplazamiento forzado masivo, individual, familiar. (CNMH, 2014, p. 46)

Finalmente, la desaparición de los jóvenes también permitía instalar un mensaje dirigido a otros, las familias y las comunidades, que eran testigos directos o indirectos de los hechos. Este mensaje implicaba dominio y poder por parte de los actores ilegales, quienes utilizaban este hecho para comunicar su presencia, su dominio y sometimiento que ejercían en la población (CNMH, 2014).

Ahora bien, ¿cuáles son los impactos psicosociales de la desaparición forzada, cuyo foco han sido principalmente jóvenes? Es importante anotar que los diferentes informes 
mencionados anteriormente, las comisiones de la verdad de Argentina (Conadep, 1984), la Comisión para el Esclarecimiento Histórico (ONU, 1999) de Guatemala, la Corporación Nacional de Reparación y Reconciliación (1996) de Chile y los análisis sobre la desaparición forzada en Colombia (CNMH, 2014) han mencionado solo en forma tangencial el asunto de los jóvenes como receptores de la desaparición forzada y sus implicaciones psicosociales para el tejido social. En este sentido, el análisis aquí presentado, enfatiza sobre este hecho particular: la desaparición de los jóvenes como un recurso sistemático de la violencia, partiendo del caso colombiano.

El primer tema es que las implicaciones psicosociales de la desaparición suponen un profundo daño ocasionado a los y las jóvenes víctimas directas y al tejido social como víctima indirecta:

Cuando un ser humano es desaparecido se inflige un sufrimiento indescriptible y se causan daños incalculables, persistentes y duraderos, en primer lugar, a los familiares de la víctima, pero también a las comunidades, a las organizaciones, al entorno de las víctimas y a la sociedad en su conjunto. (CNMH, 2016, p. 265)

Con la desaparición de una persona se propicia una especie de grieta, de ruptura, que marca el devenir sociohistórico en un antes y un después:

La desaparición forzada se inscribe como un hecho traumático, en tanto marca un antes y un después en la vida de quienes sufren esta experiencia, con la particularidad de que la ausencia queda suspendida en el tiempo y no están dadas las condiciones materiales - como la comprobación de la muerte ante la existencia de un cadáver-para la transformación de la relación entre quien se encuentra desaparecido y sus seres queridos. (CNMH, 2016, p. 272)

De acuerdo con lo planteado por los análisis del CNMH (2016), se pueden clasificar estos impactos en tres ejes: la interrupción inesperada de un proyecto de vida personal, la incertidumbre permanente de la familia y las rupturas de la vida comunitaria. En tal sentido, la desaparición forzada supone la interrupción violenta y absoluta del desarrollo y curso vital de ese joven. De manera abrupta se interrumpen sus proyectos, sus realizaciones personales, sus metas, impidiendo de manera categórica el devenir personal y social presente y futuro (CNMH, 2014).

En cuanto a la incertidumbre constante de la familia, esta proviene de ese permanente no saber nada acerca de la persona desaparecida: 
La ocultación del paradero de la víctima, de las condiciones físicas en que se encuentra, de si está aún con vida, si está siendo sometida a crueles torturas, si está entregando información sobre la organización o comunidad a las que pertenece, crea un entorno de incertidumbre que incide con carácter permanente sobre aquellos que no están capturados y que formaban parte del diario quehacer de la víctima: su familia, su partido político, su organización sindical, social, cultural o sobre los demás habitantes de la comunidad.

(ONU, 1999, p. 414)

También se establece una especie de círculo de sufrimiento y angustia que no logra romperse con facilidad. Esto implica esa continua búsqueda del ser querido y varios procesos de denuncia y de procedimientos ante la justicia (CNMH, 2014).

En suma, el sufrimiento de las familias se convierte en un escenario emocional de la vida cotidiana que, aunque se transforma, no termina y toma diferentes expresiones en cuanto a impactos en los diferentes ámbitos de la vida. Estos incluyen el quiebre de proyectos de vida o enfocarse únicamente en la búsqueda del familiar, con cuestionamientos profundos sobre la existencia y la desesperanza de un futuro incierto (CNMH, 2014). Así pues, a nivel de las rupturas en la vida comunitaria se puede dar:

Transmisión generacional del daño: la rabia y el dolor se transmite a los niños y niñas, aun siendo bebés en el momento de la desaparición del familiar. El proyecto de vida de los adolescentes y los jóvenes se altera, dado su momento vital en el que se da un proceso de consolidación de sus proyectos de vida. Todos los esfuerzos se concentran en la búsqueda de la verdad, la búsqueda de los cuerpos y la superación de la impunidad. (CNMH, 2014, p. 58)

También ocurren muchos procesos a nivel comunitario, entre los que se encuentran la estigmatización e indiferencia por parte de la sociedad:

La indiferencia de la sociedad y el manejo de los medios de comunicación que invisibilizan la desaparición, genera un quiebre con el sentido de pertenencia a la sociedad y se cuestionan los valores y premisas de convivencia en el orden social. La comunidad ve afectada las condiciones económicas que le permitan mantener calidad de vida. (CNMH, 2014, p. 58)

Madariaga (2000) lo expresa como:

La emergencia de patrones de dominación cuyo sustrato psicosocial fue la internalización masiva del miedo, la apatía e indiferencia social, la generalización de la violencia como fórmula de resolución de conflictos en todos los campos de las relaciones interpersonales, el funcionamiento anómico en la vida comunitaria, el ensimismamiento individualista. (p. 3 ) 
En este sentido, las familias y las comunidades quedan en un estado de total indefensión y aislados en una sociedad que no alcanza a dimensionar su dolor o la intensidad de su búsqueda (Grupo de psicología social crítica otras voces, 2010, p. 117).

\section{Reflexiones finales}

\section{Los jóvenes y la desaparición forzada: una tarea pendiente}

Un aspecto es claro: la desaparición forzada ha contribuido a la configuración de procesos traumáticos psicosociales en los diferentes países latinoamericanos, en donde se vivió - y aún se vive - la violencia política; tal es el caso de Colombia. En especial, cuando los datos muestran a los jóvenes como principales objetivos de este hecho victimizante, caracterizado por su sistematicidad, inhumanidad y crueldad.

$\mathrm{Al}$ respecto, hay algunos elementos que se plantean como cierre -o apertura- de esta discusión y que, al mismo tiempo, pueden representar áreas de investigación a seguir. El primero es que los jóvenes siguen siendo una figura central, socialmente representativos y simbólicos; los portadores perfectos de mensajes contundentes de dominación, miedo o sometimiento, con los que se hace eco en los demás grupos, colectivos y organizaciones. Atentar contra ellos, dominarlos, someterlos, desaparecerlos es una forma de hacerlo también con el resto de la sociedad; hecho que, además, connota unas raíces sociohistóricas que no son recientes y que más bien implican unas formas de exclusión, discriminación y selectividad social. Así lo comenta Mora (2017), a propósito del análisis de los efectos psicosociales de la desaparición de 43 estudiantes en México (2014):

Para la mayoría de los familiares de los jóvenes normalistas los hechos del 26 de septiembre no se figuran como un acto violento aislado del conjunto de las experiencias de vida, sino se insertan en una acumulación de violencias a lo largo de sus vidas. (p. 30)

También es una estrategia de contención del pensamiento crítico, de la posibilidad de dudar o plantear de manera analítica esa sociedad en la que se vive y en la que se le exige al joven cumplir una serie de estándares, normas y condiciones. Por esto, «la desaparición se enfoca en jóvenes, porque es una forma de socavar la posibilidad del pensamiento, del cambio y de la transformación» (CNMH, 2016, p. 17).

Finalmente, la desaparición de jóvenes puede representar un fuerte golpe a la esperanza de las sociedades, pues se convierte en un recordatorio, no solo de lo frágil que puede 
ser la existencia, sino de la poca fuerza o capacidad de un pueblo para seguir enfrentando las vicisitudes, las injusticias o las causas de sus problemas, a manera de recordatorios mentales permanentes que resuenan en el imaginario colectivo presente (Castillejo, 2009).

En este sentido, los investigadores tenemos una tarea pendiente: evaluar esa conexión entre desaparecer jóvenes y la afectación en el desarrollo social de un país como Colombia y las implicaciones que ello puede tener, no solo para la condición juvenil en sus expresiones identitarias y subjetivas (campesino, trabajador, líder o estudiante), sino en cuanto a las limitaciones que una comunidad puede tener en los niveles productivos, económicos y sociales en la perspectiva de desarrollo.

Adicionalmente, otra tarea pendiente es la que refiere a los procesos de resignificación, reparación y reconstrucción del tejido social para sanar el sufrimiento y los impactos psicosociales anteriormente descritos. En tal sentido, la voz de los jóvenes puede y debe tener espacios en la sociedad para exponer sus puntos de vista, para discutir sus ideas y para definir sus propias estructuras de pensamiento y acción. Esa voz puede darse de forma directa, en el caso de sobrevivientes de la desaparición forzada, pero también puede ser indirecta, desde la memoria de las familias, quienes pueden expresar en el ámbito de lo público las ideas, sentimientos, sueños y posibilidades de esos jóvenes a los cuales se les arrebató la vida (Guatavita, 2014, p. 51).

Entonces, no solo se tratará de medidas de reparación establecidas en cuanto a los daños, en términos de la responsabilidad estatal frente a las violaciones que se presentaron (como lo indica Arévalo, 2010), sino también la obligación de la sociedad latinoamericana en repensar, reubicar y resignificar ese lugar que se le ha dado históricamente a los jóvenes, así como los propios procesos de cambio, transformación y crítica a los sistemas sociales, económicos y políticos que se han ido instalando en Latinoamérica. En palabras de Beristain y Dona (1999), la tarea es ardua y requiere, entre muchos otros elementos, hablar de verdades que duelen, poner a la altura la experiencia de la gente (en este caso de las familias de los jóvenes desaparecidos), salir del silencio, verse en el espejo de otros.

En este sentido, los investigadores han recogido cientos de experiencias de reivindicación de lo humano y de la vida a partir de los rostros, particularmente de mujeres sobrevivientes, que se han encontrado para ser la voz y la imagen no solo de sí mismas, sino de sus hijos, sus familias y sus comunidades. Es una construcción subjetiva que nace del dolor, pero también del encuentro, del diálogo y del reconocimiento del otro. Así lo reconoce el Colectivo Nacional de Mujeres (2016) cuando afirma que las mujeres han 
mostrado procesos autónomos de recuperación de las personas y colectivos de paz desde el cuidado, los afectos y la acción política.

También lo reconoce Ospina (2017) cuando afirma que lo silenciado puede ser escuchado y que esta puesta en voz viva de lo vivido nos puede ayudar a escudriñar esas profundas raíces sociales, históricas y políticas como una forma de desprivatización del daño. Muchas comunidades cuasianiquiladas por la violencia recomponen sus lazos sociales en el proceso mismo de reconstrucción de las dinámicas del conflicto y las preguntas por el futuro. Las víctimas se organizan en comunidades de duelo, comunidades de restitución de derechos y comunidades para reclamar el acceso a derechos sociales y políticos más amplios (Sánchez, 2018, p. 107).

De la misma forma, la participación de los jóvenes en espacios de memoria, resignificación y construcción de alternativas de convivencia ha contribuido en estos procesos de comprensión de lo vivido que, al mismo tiempo, son sanadores y reveladores de alternativas sociales de transformación. Así lo planteó Amador-Baquiro (2016) en su investigación con jóvenes víctimas del conflicto armado:

La narrativa visual no solo opera como testimonio, sino como un nuevo estadio biográfico que desordena la secuencia ideal del sujeto joven integrado a la educación o al trabajo, y en el que se radicaliza su construcción tánato-biográfica en el espacio público. (p. 1325)

Finalmente, es necesario reconocer esas mismas condiciones contextuales en relación a los jóvenes y sus procesos de subjetivación, que indiscutiblemente se han desarrollado en niveles macro y microsociales (Blanco et al., 2018); estas, al mismo tiempo les han marcado un devenir violento, negado, invisibilizado, en el que también se les hace exigencias en su rol protagónico y dinámico ante la misma sociedad, que les estigmatiza, les niega y les cierra las posibilidades (Muñoz, como es citado por Jiménez-Flórez, 2015).

En otras palabras, se trata de abrir los espacios y ofrecer diversidad de lugares físicos y simbólicos a los jóvenes, pues, más allá de una condición cronológica, esta implica una condición sociohistórica que es central en el tejido social, en la reconstrucción del mismo y en los procesos de construcción de paz y convivencia que el país enfrenta, aún en medio del conflicto que persiste. 


\section{Agradecimientos}

Este artículo se construyó como parte del proceso de revisión teórica, reflexión y análisis de la problemática de desaparición forzada y trauma psicosocial en el marco de los estudios doctorales en el Centro de Estudios Avanzados de la Fundación Centro Internacional de Educación y Desarrollo Humano y la Universidad de Manizales. Por lo que agradecemos a este programa por abrir la posibilidad de construcción de conocimiento social, desde estos niveles de formación doctoral. También hacemos un reconocimiento a los miles de jóvenes que, en su calidad de campesinos, trabajadores, líderes sociales, estudiantes, población LGBTI o cualquier otra condición personal, social o subjetiva fueron víctimas directas de este hecho victimizante en Colombia en los últimos 40 años.

\section{Referencias}

Amador-Baquiro, J. C. (2016). Jóvenes, temporalidades y narrativas visuales en el conflicto armado colombiano. Revista Latinoamericana de Ciencias Sociales, Niñez y Juventud, $14(2), 1313-1329$.

Arévalo, L. (2010). Atención psicosocial y reparación en contextos de violencia sociopolítica: una mirada reflexiva. Revista de Estudios Sociales, (36), 29-39. https://doi.org/g8x2

Beristain, C. (2018). Impactos, desafíos y aportes en un enfoque psicosocial del Remhi. Naciones Unidas.

Beristain, C. M., \& Dona, G. (1999). Reconstruir el tejido social: un enfoque crítico de la ayuda humanitaria (vol. 146). Icaria Editorial.

Blanco, A., De La Corte, L., \& Sabucedo, J. M. (2018). Para una psicología social crítica no construccionista: reflexiones a partir del realismo crítico de Ignacio MartínBaró. Universitas Psychologica, 17(1), 5-29. https://doi.org/g8x3

Blanco, A., \& Díaz, D. (2004). Bienestar social y trauma psicosocial: una visión alternativa al trastorno de estrés postraumático. Clínica y Salud, 15(3), 227-252.

Bernal-Torres, C. A. (2016). Metodología de la investigación. Pearson.

Betancur, L., \& Castro, G. (2015). Experiencias e impactos de la violencia política contra mujeres en el centro y norte del Valle del Cauca. La Manzana de la Discordia, 1o(1), 99-111. https://dx.doi.org/10.25100/lamanzanadeladiscordia.v10i1.1598

Calveiro, P. (2014). Poder y desaparición: los campos de concentración en Argentina. Colihue.

Castillejo, A. (2009). Los archivos del dolor: ensayos sobre la violencia y el recuerdo en la Sudáfrica contemporánea. Ediciones UniAndes. 
Centro Nacional de Memoria Histórica. (2014). Entre la incertidumbre y el dolor: impactos psicosociales de la desaparición forzada. Autor.

Centro Nacional de Memoria Histórica. (2016). Hasta encontrarlos: el drama de la desaparición forzada en Colombia. Autor.

Centro Nacional de Memoria Histórica. (2018). Desaparición forzada: balance de la contribución del CNMH al esclarecimiento histórico. Autor.

Colectivo Nacional Mujeres. (2016). Sanando heridas entre mujeres: experiencias de recuperación psicosocial y construcción de paz de mujeres colombianas. Conferencia Nacional de Organizaciones Afrocolombianas; Narrar Para Vivir.

Comisión Nacional sobre la Desaparición de Personas. (1984). Informe nunca más. Eudeba. Corporación Nacional de Reparación y Reconciliación. (1996). Informe de la Comisión Nacional de Verdad y Reconciliación. Autor.

Dobles, I. (2009). Memorias del dolor: consideraciones acerca de las comisiones de la verdad en América Latina. Arlekín.

Franco, S. (2018). Memoria y verdad para la salud y la paz. Asociación Colombiana de Salud Pública. Gómez, P. B. (2015). Subjetividades colectivas y prácticas de paz en contextos de guerra: una perspectiva desde la psicología política decolonial. Prospectiva, Revista de Trabajo Social e Intervención Social, (20), 71-90.

Grupo de Psicología Social Crítica Otras Voces. (2010). Del dolor a la propuesta: voces del panel de víctimas. Revista de Estudios sociales, (36), 114-115. https://doi.org/g8x6

Guatavita, A. (2014). La construcción de sentido de la desaparición forzada en el proceso de memoria de hijos e hijas en Colombia [Tesis de maestría, Universidad Nacional de La Plata]. Memoria Académica. https://bit.ly/3pLNKFf

Hernández, P., \& Blanco, A. (2005). Violencia política y trauma psicosocial. En A. Blanco, del Águila, R., \& J. M. Sabucedo (Eds.), Madrid 11-M: un análisis del mal y sus consecuencias (pp. 281-310). Trotta.

Instituto Nacional de Salud. (2017). Consecuencias del conflicto armado en la salud en Colombia. Jiménez-Flórez, M. (2015). Ser joven en Colombia: subjetividades, nuevas tecnologías y conflicto armado. Entrevista a Germán Muñoz. Revista Latinoamericana de Ciencias Sociales, Niñez y Juventud, 13(1), 437-445.

Lira, E. (2010). Trauma, duelo, reparación y memoria. Revista de Estudios Sociales, (36), 14-28. https://doi.org/10.7440/res36.2010.02

Lira, E., \& Castillo, M. I. (1991). Psicología de la amenaza política y del miedo. Instituto Latinoamericano de Salud Mental y Derechos Humanos. 
Madariaga, C. (2000). Trauma psicosocial, trastorno de estrés postraumático y tortura. Red Salud DD. HH.; ECAP; ODHAG; IRCT.

Martín-Baró, I. (1988). La violencia política y la guerra como causas del trauma psicosocial en el Salvador. Revista de Psicología de El Salvador, (28), 123-141.

Martín-Baró, I. (1990). Psicología social de la guerra: trauma y terapia. UCA Editores.

Mignorance, F., \& Arellana, E. (2019). Cartografía de la desaparición forzada en Colombia: relato (siempre) incompleto de lo invisibilizado. Human Rights Everywhere.

Mollica, R. (1999). Efectos psicosociales y sobre salud mental de las situaciones de violencia colectiva. En P. Pérez (Ed.), Actuaciones psicosociales en guerra y violencia política (pp. 45-63). Exlibris.

Mora, M. (2017). Desaparición forzada, racismo institucional y pueblos indígenas en el caso Ayotzinapa, México. Lasaforum, 48(2), 29-30.

Moyano, M. (2009). Análisis de los efectos psicosociales de la violencia política en tres distritos del departamento de Huancavelica con distintos niveles de afectación [Tesis de pregrado]. Pontificia Universidad Católica del Perú.

Organización de Naciones Unidas. (1993). De la locura a la esperanza: la guerra de 12 años en El Salvador. Comisión de la Verdad para El Salvador.

Organización de Naciones Unidas. (1999). Guatemala: memoria del silencio. Autor.

Ortega, F. (Ed.) (2011). Trauma, cultura e historia: reflexiones interdisciplinarias para el nuevo milenio. Universidad Nacional de Colombia.

Ospina, A. (2017). La verdad de las mujeres en escena: sistematización del proceso de acompañamiento psicosocial con herramientas de teatro-pedagogía a mujeres testimoniantes de la Comisión de Verdad y Memoria de la Ruta Pacifica. Nuevo Milenio.

Posada, R., \& Parales, C. J. (2012). Violencia y desarrollo social: más allá de una perspectiva de trauma. Universitas Psychologica, 11(1), 255-267. https://doi.org/g8x8

Registro Único de Víctimas. (2021). Red nacional de información. https://bit.ly/zase815

Sánchez, G. (2018). Reflexiones sobre genealogía y políticas de la memoria en Colombia. Análisis Político, (92), 96-114. https://doi.org/10.15446/anpol.v31ng2.71101

Trucco, D., \& Ullmann, H. (eds.) (2015). Juventud: realidades y retos para un desarrollo con igual. Comisión Económica para América Latina y el Caribe.

Uribe, A. (2009). Perfiles del mal en la historia de Colombia. Universidad Nacional de Colombia. Vasco, C. E. (1990). Tres estilos de trabajo en las ciencias sociales. Centro de Investigación y Educación Popular.

Yubero, S., Larrañaga, E., \& Blanco, A. (Coords.) (2007). Convivir con la violencia. Ediciones de la Universidad Castilla-La Mancha. 